\title{
铜催化的非活化烯烃的不对称烷胺化反应
}

\author{
王紫璇李必杰*
}

(清华大学化学系基础分子科学中心 北京 100084)

\section{Cu-Catalyzed Asymmetric Alkylamination of Unactivated Alkenes}

\author{
Wang, Zixuan Li, Bijie*
}

(Center of Basic Molecular Science, Department of Chemistry, Tsinghua University, Beijing 100084)

烯烃是有机化合物中最基本的官能团之一, 烯烃的 双官能团化是快速构建复杂分子的重要方法 ${ }^{[1]}$. 虽然烯 烃的不对称催化转化取得了长足的发展, 但非活化烯 烃 ${ }^{[2]}$ 尤其是非活化内烯烃的不对称催化转化仍然具有相 当的挑战性 ${ }^{[3]}$. 非活化内烯烃的反应活性很低, 并且其 不对称催化转化过程涉及到多种选择性的控制, 包括区 域选择性、非对映选择性及对映选择性.

近年来, 配位辅助策略在非活化烯烃不对称催化转 化领域得到了广泛应用 ${ }^{[4]}$. 配位基团辅助烯烃发生迁移 插入或亲核金属化过程，形成环状烷基金属中间体，然 后发生后续转化得到单官能化 ${ }^{[5]}$ 或双官能化 ${ }^{[6]}$ 产物. 最
近，铜催化的自由基反应为非活化端烯的不对称双官能 团化提供了新的方法 ${ }^{[7]}$. 烯烃与贫电子自由基反应形成 新的烷基自由基，再发生立体选择性的分子内反应得到 手性产物. 然而目前该类方法中非活化烯烃的碳官能团 化主要局限于芳基、酰基、炔基和特殊烷基对烯烃的加 成 ${ }^{[8]}$, 普通烷基对非活化烯烃的不对称加成还有待于进 一步发展 ${ }^{[9]}$.

近日，南开大学化学学院陈弓、何刚团队报道了通 过铜催化的烷基自由基不对称加成实现的非活化烯烃 的不对称双官能团化反应(Scheme 1). 该研究团队利用 一价铜作为催化剂, 5-碘-8-氨基喹啉作为配位辅助基团,<smiles>CCOC(=O)C1=C(C)NC(C)=C(C(=O)OCC)C1O</smiles>

alkyl donor<smiles>[R]C=CCC(=O)Nc1ccc(I)c2cccnc12</smiles>
(IQ) unactivated internal alkene cat. $\mathrm{Cu}(\mathrm{MeCN})_{4} \mathrm{PF}_{6} / \mathrm{L}$ $\underset{\mathrm{DCM}, 30^{\circ} \mathrm{C}}{\mathrm{AdO}_{2} \mathrm{CO}_{2}{ }^{\circ} \mathrm{Bu}}$ $\beta$-lactams up to $96 \%$ ee<smiles>O=P(O)(c1ccccc1)c1ccc2c(c1-c1c(P(=O)(c3ccccc3)c3ccccc3)ccc3c1OCO3)OCO2</smiles>

chiral ligands<smiles>O=P(c1ccccc1)(c1ccccc1)c1cc([Al])c2ccccc2c1-c1c(P(=O)(c2ccccc2)c2ccccc2)cc([Al])c2ccccc12</smiles>

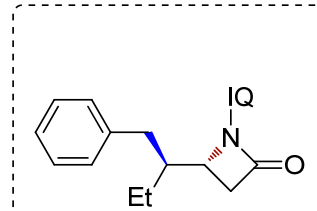

$72 \%, 97: 3$ er Scope of benzyl-DHP<smiles>CCC(Cc1ccccc1Cl)C1CC(=O)N1O</smiles>

$63 \%, 97: 3$ er

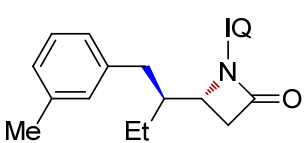

$68 \%, 97: 3$ er Scope of alkyl-DHP

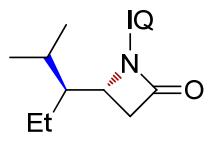
$72 \%, 95: 5$ er


81\%, 95:5 er

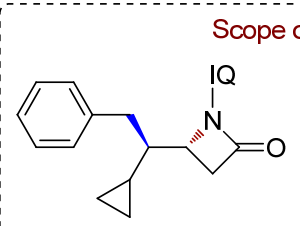

$62 \%, 94: 6$ er

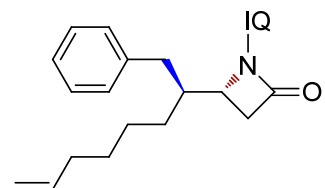

$61 \%, 95: 5$ er



$62 \%, 91: 9 \mathrm{er}$

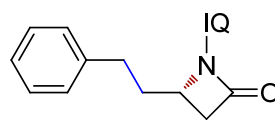

70\%, 98:2 er

图式 1 铜催化的非活化烯烃与烷基自由基的不对称双官能团化反应

Scheme 1 Cu-catalyzed enantioselective difunctionalization with alkyl radical

* Corresponding author. E-mail: bijieli@mail.tsinghua.edu.cn. Published online February 18, 2021. 
4-烷基 Hantzsch 酯(DHP)作为烷基供体, 联芳基二氧化 膦为手性配体, 实现了非活化烯烃的不对称烷胺化反 应, 高效构建了一系列含有两个连续手性中心的 $\beta$ 内酰 胺类化合物.

该方法条件温和，对苯环上连有多种取代基的苄基 Hantzsch 酯、普通的二级甚至三级烷基 Hantzsch 酯都有 很好的兼容性. 此外, 带有不同取代基的顺式内烯烃和 端烯均可以顺利反应, 以良好到优异的收率、单一的非 对映选择性和较高的对映选择性得到 $\beta$ 内酰胺产物. 值 得指出的是, 该方法可以实现 $\beta$ 内酰胺产物的克级制备. 产物中的导向基团也可以高效脱除, 并经过后续的转化 获得手性氨基酸衍生物、手性 $\beta$-硫代内酰胺以及 $N$-芳 基化产物 ${ }^{[10]}$.

实验及密度泛函理论(DFT)计算的研究表明, 该反 应经历了自由基介导的机制. 首先, 一价铜催化剂与氧 化剂进行单电子转移(SET)生成叔丁氧自由基和二价铜. 底物中的烯烃和导向基团同时与二价铜配位形成络合 物. 叔丁氧自由基与烷基 Hantzsch 酯反应生成烷基自由 基. 之后烷基自由基与二价铜/烯烃络合物发生亲核 (Wacker 型)加成形成三价铜金属环中间体. 该加成过程 是决定反应对映选择性的关键步骤. 随后经过分子内的 还原消除得到 anti 选择性的加成产物 $\beta$ 内酰胺(Scheme 2).

陈弓、何刚团队利用一价铜催化剂, 结合氨基喹啉 配位基团和联芳基膦氧手性配体, 实现了普通烷基自由 基对非活化内烯烃的不对称加成. 该策略可以构建其他 方法难以合成的复杂 $\beta$ 内酰胺化合物. 与此前报道的铜 催化自由基对末端烯烃的不对称加成反应不同的是, 铜 在烷基自由基对内烯烃加成时就起到了对映选择性的
控制作用，从而同时在烯烃两端控制立体化学，构建连 续手性中心. 该方法为非活化烯烃的高效利用提供了新 的思路.

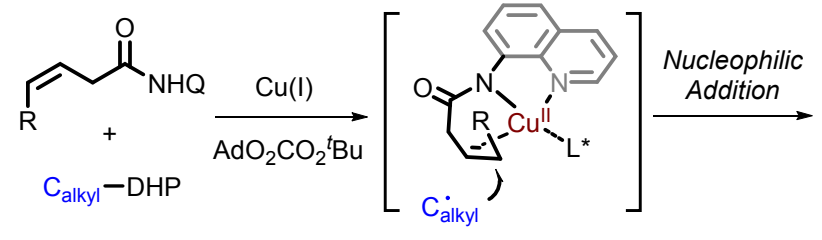

enantio-determining

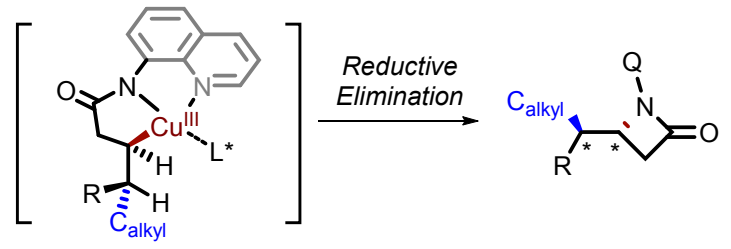

图式 2 反应立体选择性的控制

Scheme 2 Control of stereoselectivity

\section{References}

[1] Dhungana, R. K.; KC, S.; Basnet, P.; Giri, R. Chem. Rec. 2018, 18 , 1314.

[2] Coombs, J. R.; Morken, J. P. Angew. Chem., Int. Ed. 2016, 55, 2636.

[3] Chen, J.; Lu, Z. Org. Chem. Front. 2018, 5, 260.

[4] Wang, Z.-X.; Bai, X.-Y.; Li, B.-J. Chin. J. Chem. 2019, 37, 1174.

[5] Shen, H.-C.; Zhang, L.; Chen, S.-S.; Feng, J.; Zhang, B.-W.; Zhang, Y.; Zhang, X.; Wu, Y.-D.; Gong, L.-Z. ACS Catal. 2019, 9, 791.

[6] Liu, Z.; Li, X.; Zeng, T.; Engle, K. M. ACS Catal. 2019, 9, 3260.

[7] Li, Z.-L.; Fang, G.-C.; Gu, Q.-S.; Liu, X.-Y. Chem. Soc. Rev. 2020 49,32 .

[8] Wang, F.; Chen, P.; Liu, G. Acc. Chem. Res. 2018, 51, 2036.

[9] Shi, P.; Wang, J.; Gan, Z.; Zhang, J.; Zeng, R.; Zhao, Y. Chem. Commun. 2019, 55, 10523.

[10] Bai, Z.; Zhang, H.; Wang, H.; Yu, H.; Chen, G.; He, G. J. Am. Chem. Soc. 2021, 143, 1195.

(Cheng, F.) 